\title{
ESTADÍSTICAS DE ARTÍCULOS - 2020
}

Artículos recibidos

\begin{tabular}{|c|c|c|c|c|c|c|}
\hline & \multicolumn{2}{|c|}{ Didáctica de las Matemáticas } & \multicolumn{2}{|c|}{ Didáctica de las Ciencias } & \multicolumn{2}{|c|}{ Total } \\
\hline Artículos recibidos en 2020 & \multicolumn{2}{|c|}{79} & \multicolumn{2}{|c|}{184} & \multicolumn{2}{|c|}{263} \\
\hline $\begin{array}{l}\text { Artículos que pasan } \\
\text { a evaluación por pares }\end{array}$ & 44 & $55,70 \%$ & 59 & $32,07 \%$ & 103 & $39,16 \%$ \\
\hline $\begin{array}{l}\text { Artículos que no pasan } \\
\text { a evaluación }\end{array}$ & 35 & $44,30 \%$ & 125 & $67,93 \%$ & 160 & $60,84 \%$ \\
\hline
\end{tabular}

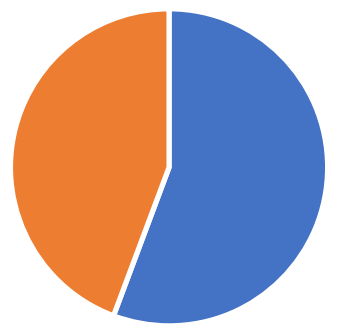

Didáctica de las Matemáticas

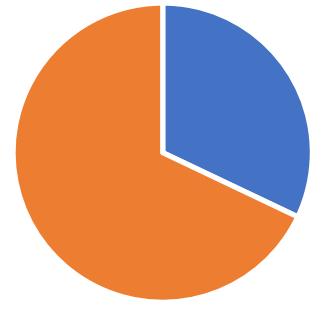

Didáctica de las Ciencias

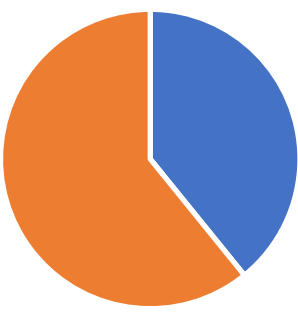

Total

Artículos evaluados

\begin{tabular}{|c|c|c|c|c|c|c|}
\hline & \multicolumn{2}{|c|}{ Didáctica de las Matemáticas } & \multicolumn{2}{|c|}{ Didáctica de las Ciencias } & \multicolumn{2}{|c|}{ Total } \\
\hline Artículos evaluados en 2020 & \multicolumn{2}{|c|}{44} & \multicolumn{2}{|c|}{59} & \multicolumn{2}{|c|}{103} \\
\hline No publicables & 35 & $75,00 \%$ & 29 & $49,15 \%$ & 62 & $60,19 \%$ \\
\hline Aceptados & 7 & $15,91 \%$ & 26 & $44,07 \%$ & 33 & $32,04 \%$ \\
\hline (1) En evaluación & 4 & $9,09 \%$ & 4 & $6,78 \%$ & 8 & $7,77 \%$ \\
\hline
\end{tabular}

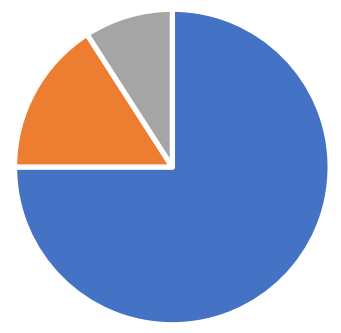

Didáctica de las Matemáticas

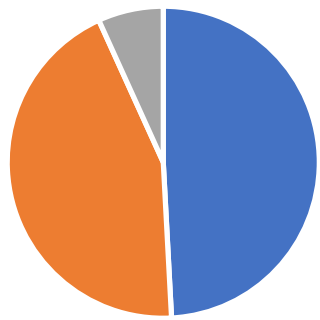

Didáctica de las Ciencias

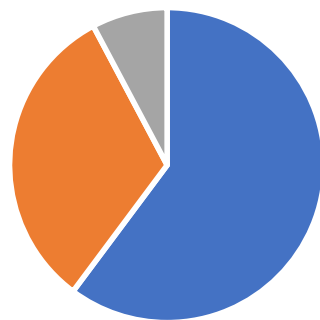

Total 
